\title{
Form ever follows function
}

\author{
Kenton J. Zehr, MD
}

\author{
From the Division of Cardiac Surgery, Johns Hopkins Hospital, Baltimore, Md. \\ Disclosures: Author has nothing to disclose with regard to commercial support. \\ Received for publication Aug 26, 2015; accepted for publication Aug 26, 2015; available ahead of print Oct 6, \\ 2015 . \\ Address for reprints: Kenton J. Zehr, MD, Johns Hopkins Hospital, 1800 Orleans St, Baltimore, MD 21287 \\ (E-mail: zehr@jhmi.edu). \\ J Thorac Cardiovasc Surg 2016;151:120-1 \\ 0022-5223/\$36.00 \\ Copyright (c 2016 by The American Association for Thoracic Surgery \\ http://dx.doi.org/10.1016/j.jtcvs.2015.08.098
}

Whether it be the sweeping eagle in his flight, or the open apple-blossom, the toiling work-horse, the blithe swan, the branching oak, the winding stream at its base, the drifting clouds, over all the coursing sun, form ever follows function, and this is the law. Where function does not change, form does not change.... It is the pervading law of all things organic and inorganic, of all things physical and metaphysical, of all things human and all things superhuman, of all true manifestations of the head, of the heart, of the soul, that the life is recognizable in its expression, that form ever follows function. This is the law. -Louis Sullivan ${ }^{1}$

American architect Louis Sullivan introduced the phrase "form ever follows function" while observing the natural world. ${ }^{1}$ Leonardo da Vinci understood this well. Take his detailed drawings of the aortic root and his experiments with the functionality of the aortic valve and aortic root in relation to blood flow. ${ }^{2}$ Da Vinci elegantly hypothesized that the vortices occurring within the sinuses of Valsalva play a role in closure of the aortic valve. ${ }^{3}$ It is from his preserved notes and drawings that the hypothesis of the functionality of the sinuses of Valsalva arose.

It has been hypothesized that the sinuses keep the coronaries primed with blood during systole. Reid ${ }^{4}$ observed that in the fleetest animals (dog and human) the coronary ostia is located closer to the sinotubular ridge to exploit a surge effect of the blood leaving the ventricle in systole. However, sinuses are present in the pulmonary root and the venous valve apparatuses that have no vessels emanating from them. Thus, the prevailing hypothesis is that the sinuses serve as pressure recovery chambers that initiate a smooth valve closure aided by the vortices within them. This was clearly shown in the rarely cited but elegant work of Giulio Ceradini in $1872 .^{5}$ Ceradini developed an ex vivo pulse duplicator to observe the behavior of the semilunar valves during the cardiac cycle with the flow patterns accentuated by the yellow spores of Lycopodium clavatum (Figure 1). He wrote, "During the systolic efflux the axial flow component provokes the semi-opening of the

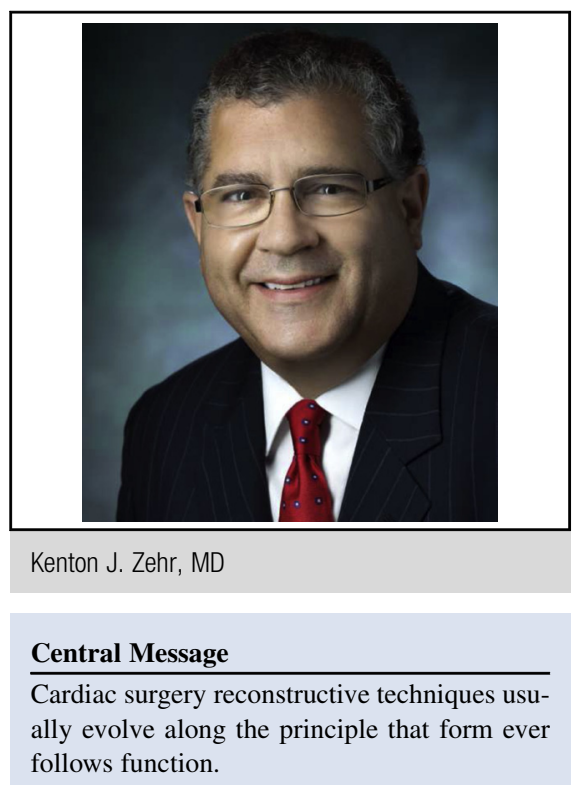

See Article page 112 . valves while the centripetal eddies in the Valsalva sinuses do not permit a total opening of the semilunar valves because they tend to produce a closure position. When the efflux decelerates the centripetal eddies continue and provoke the closure of the valves." 6 In more recent literature, Bellhouse and colleagues ${ }^{7}$ confirmed the vortices and hypothesized a fluid dynamic control mechanism that positions the cusp at a distance from the wall of the aorta so that the slightest reversal of flow will close the valve. Simply put, should the cusp touch the aortic wall it would require considerable reversed flow to close the valve.

During the past 3 decades remarkable experimental work has advanced our understanding of aortic valve function in relation to the complexity of the aortic root and the role of the sinuses of Valsalva in facilitating smooth aortic valve opening and valve closure. ${ }^{8-14}$

Surgical reconstructive techniques usually evolve along the principle that form ever follows function with progressively better long-term results; for example, the ball-and-cage valve design to a tricuspid morphology, the Vineberg revascularization procedure to direct coronary revascularization with arterial conduits, mitral valve replacement to mitral valve repair, and nodal ablation to the Cox-maze III procedure. The valve-sparing aortic root reconstruction operation has evolved with our understanding. ${ }^{15}$ When Sarsam and Yacoub ${ }^{16}$ introduced what is now referred to as the remodeling technique, the idea 


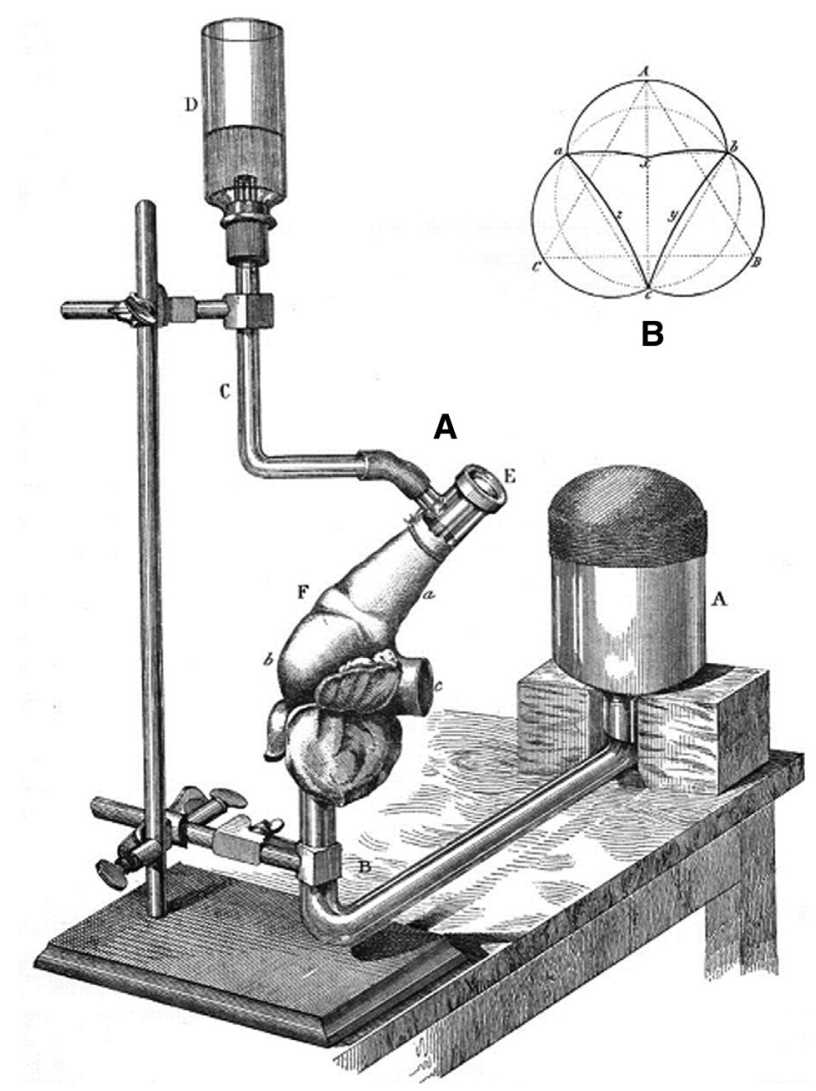

FIGURE 1. A, Ceradini's device to stimulate heart valve function. $\mathrm{B}$, Pulmonary valve in equilibrium.

was to recreate normal root anatomy and preserve normal aortic valve function. The procedure was complex and required considerable intraoperative technical judgment. The tendency for the neosinuses to splay over time resulted in unpredictable durability. David and Feindel's reimplantation technique ${ }^{17}$ served 2 important purposes: it solved the problem of stabilization of the base of the aortic root and it simplified the operation so that durable results could be achieved by many surgeons.

Proponents of the remodeling technique espoused the theoretical benefits of a more morphologically normal aortic root and proponents of the reimplantation procedures argued the benefits of more universal applicability and more reproducible results. There is good evidence that the aortic valve is less stressed in patients with neosinuses. ${ }^{18,19}$ In 1995, Cochran and colleagues ${ }^{20}$ presented a tailored modification of the reimplantation procedure that created a pseudosinus. In 1999, Thubrikar and Robicsek developed a novel sinus graft that was applied clinically as a remodeling technique in $2000 .{ }^{21}$ These and other modifications added complexity instead of simplifying the procedure. Then, in 2001, De Paulis and colleagues ${ }^{22}$ presented a series using a commercially produced prosthetic Valsalva graft that combined the theoretical advantages of neosinuses with a less technically challenging reimplantation technique. This graft rapidly became the most-used prosthesis for valve-sparing aortic root reconstructive procedures. Fifteen years after introduction of the sinus graft, we are now privy to a long-term, single-center series of 124 patients using a consistent approach. ${ }^{23}$ The results are encouraging: $90 \%$ freedom from reoperation and $96 \%$ freedom from significant aortic regurgitation at 10 years. ${ }^{23}$ This valve-sparing aortic root reconstruction technique is appropriately part of the sinus of Valsalva story.

\section{References}

1. Sullivan LH. The tall office building artistically considered. Lippincott's Magazine. 1896;57:403-9.

2. Robicsek F. Leonardo da Vinci and the sinuses of Valsalva. Ann Thorac Surg 1991;52:328-35.

3. Gharib M, Kremers D, Koochesfahani MM, Kemp M. Experiments in Fluids. 2002;33:219-23

4. Reid K. The anatomy of the sinus of Valsalva. Thorax. 1970;25:79-85.

5. Ceradini G. Der Mechanismus der halbmondformigen Herzklappen. Mit einer lithographirteen Tafel. Leipzig, Germany: Verlag von S Hirzel; 1872:34-45.

6. Troiani D, Manni E. The work by Giulio Ceradini in explaining the mechanism of semilunar cardiac valve function. Adv Physiol Educ. 2011;35:110-3

7. Bellhouse RJ, Bellhouse FH, Reid KG. Fluid mechanics of the aortic root with application to coronary flow. Nature. 1968;219:1059-61.

8. Thubrikar MJ, Nolan SP, Aouad J, Deck JD. Stress sharing between the sinus and leaflets of canine aortic valve. Ann Thorac Surg. 1986;42:434-40.

9. Robicsek F, Thubrikar MJ. Role of sinus wall compliance in aortic leaflet function. Am J Cardiol. 1999;84:944-6.

10. Kilner PJ, Yang GZ, Wilkes AJ, Mohiaddin RH, Firmin DN, Yacoub MH. Asymmetric redirection of flow through the heart. Nature. 2000;404:759-61.

11. Lansac E, Lim HS, Shomura Y, Lim KH, Rice NT, Goetz WA, et al. Aortic rott dynamics are asymmetric. J Heart Valve Dis. 2005;14:400-7.

12. Cheng A, Dagum P, Miller DC. Aortic root dynamics and surgery: from craft to science. Philos Trans R Soc Lond B Biol Sci. 2007;362:1407-19.

13. Katayama S, Umetani N, Sugiura S, Hisada T. The sinus of Valsalva relieves abnormal stress on aortic valve leaflets by facilitating smooth valve closure. $J$ Thorac Cardiovasc Surg. 2008;136:1528-35.

14. De Paulis R, Salica A, Psiani G, Morbiducci U, Weltert L, Masilli D. Hemodynamics of the aortic valve and root: implications for surgery. Ann Cardiothorac Surg. 2013;2:40-3.

15. Miller DC. Valve-sparing aortic root replacement in patients with the Marfan syndrome. J Thorac Cardiovasc Surg. 2003;125:773-8.

16. Sarsam MA, Yacoub M. Remodeling of the aortic valve anulus. J Thorac Cardiovasc Surg. 1993;105:435-8.

17. David TE, Feindel CM. An aortic valve-sparing procedure for patients with aortic incompetence and aneurysm of the ascending aorta. J Thorac Cardiovasc Surg. 1992;103:617-21.

18. Leyh RG, Schmidtke C, Sievers HH, Yacoub MH. Opening and closing characteristics of the aortic valve after different types of valve-preserving surgery. Circulation. 1999;100:2153-60.

19. Grande-Allen KJ, Cochran RP, Reinhall PG, Kunzelman KS. Recreation of sinuses is important for sparing the aortic valve: a finite element study. $J$ Thorac Cardiovasc Surg. 2000;119:753-63.

20. Cochran RP, Kunzelman KS, Eddy AC, Hofer BO, Verrier ED. Modified condui preparation creates a pseudosinus in an aortic valve-sparing procedure for aneurysm of the ascending aorta. J Thorac Cardiovasc Surg. 1995;109:1049-58.

21. Zehr KJ, Thubrikar MJ, Gong GG, Headrick JR, Robicsek F. Clinical introduction of a novel prosthesis for valve-preserving aortic root reconstruction for annuloaortic ectasia. J Thorac Cardiovasc Surg. 2000;120:692-8.

22. De Paulis R, De Matteis GM, Nardi P, Scaffa R, Buratta MM, Chiariello L. Opening and closing characteristics of the aortic valve after valve-sparing procedures using a new aortic root conduit. Ann Thorac Surg. 2001;72: 487-94.

23. De Paulis R, Chirichilli I, Scaffa R, Weltert L, Maselli D, Salica A, et al. Longterm results of the valve reimplantation technique using a Dacron graft with sinuses. J Thorac Cardiovasc Surg. 2016;151:112-9. 